\title{
KAJIAN EKSPLANASI TARU MENYAN PENETRAL BAU MAYAT
}

\author{
I Nyoman Try Upayogi \\ STKIP Citra Bakti, Ngada \\ Email: upayogitry@gmail.com
}

\begin{abstract}
Abstrak
Peluruhan (dekomposisi) adalah salah satu proses yang terjadi setelah kematian dari makhluk hidup. Selama proses dekomposisi, tubuh akan memancarkan zat-zat dalam bentuk gas yang menyebabkan bau menyengat. Secara umum, setiap proses penguraian mayat akan memancarkan bau yang tidak sedap untuk dicium. Namun di Desa Trunyan ada keanehan, jenazah yang diletakkan di bawah pohon besar tidak akan mengeluarkan bau busuk yang biasanya tercium ketika mayat membusuk. Penduduk setempat menyebut pohon itu sebagai Taru Menyan. Artikel ini akan menjelaskan secara ilmiah faktor-faktor yang menyebabkan tidak ada bau busuk dari mayat-mayat yang ditempatkan di bawah Taru Menyan. Dalam konteks penjelasan ilmiah, ada tiga faktor eksternal yang menghambat laju penguraian jenazah di bawah Taru Menyan. Melambatnya laju dekomposisi menyebabkan mayat tidak mengeluarkan bau busuk yang biasanya tercium pada mayat biasa. Jika itu dapat dianggap sebagai filosofi pembusukan, maka proses hilangnya bau busuk dari mayat di bawah Taru Menyan dapat dijelaskan secara ilmiah.
\end{abstract}

Kata kunci : desa trunyan, taru menyan, dekomposisi, bau mayat

\begin{abstract}
Abstrak
Decay (decomposition) is one of the processes that occur after death from living body. During the decomposition process, the body will emit substances in the form of gases that cause strong stench. In general, every process of decomposition of a corpse will emit an unpleasant odor to smell. But in Trunyan Village there is an oddity,the corpse that placed under a large tree will not emit the stong stench that is commonly smell when a corpse decomposing. Local residents refer to the tree as Taru Menyan. This article will explain scientifically the factors that caused no stench from the corpses placed under the Taru Menyan. In the context of scientific explanations, there are three external factors that hinder the rate of decomposition of the corpse under the Taru Menyan. The slowing down of the decomposition rate causes the corpse not to emit the stench that is usually smell on a common corpse. If it can be considered a decay philosophy, then the process of loss of foul odor from a dead body under the Taru Menyan can be explained scientifically.
\end{abstract}

Key Words : trunyan village, taru menyan, decomposition, corpse' stench

\section{Pendahuluan}

Manusia disebut makhluk multidimensional karena memiliki banyak dimensi dalam dirinya sendiri, seperti keindividualan, kesosialan, kesusilaan, dan keberagamaan (Tirtarahardja dan La Sulo, 1985:16), bahkan Gasset (Sastrapratedja (ed.), 1982:101) mengusulkan satu dimensi lagi, yaitu dimensi kesejarahan. Pada dimensi individualnya, manusia memiliki potensi menjadi dirinya sendiri yang berbeda dari individu lain. Pada dimensi kesosialannya, manusia memiliki potensi untuk hidup bersama orang lain yang meniscayakan mengembangkan nilai kemanusiaan. Manusia juga memiliki potensi kesusilaan atau moralitas, berupa pengetahuan tentang yang baik dan yang buruk. Dimensi keberagamaan manusia ditentukan oleh hakikatnya sebagai makhluk religius yang meyakini kekuatan supranatural di luar dirinya. Kemudian, dimensi kesejarahan bahwa manusia memiliki pengalaman masa lalu dan masa kini, serta merencanakan masa depannya. Dimensi kemanusiaan yang plural itu berada dalam diri manusia yang satu sehingga disebut monopluralis. Manusia adalah kesatuan utuh antara jiwa 
dan raga; individu sekaligus sosial; bebas sekaligus liar; dan esensi sekaligus eksistensi (Sukarma, 2017).

Bali merupakan satu dari provinsi yang ada di Indonesia yang banyak keunikan dibandingkan dengan provinsi lainnya karena memiliki kelebihan yang berbeda. Perbedaan itu telah terlihat pada ikhwal sebelum kemerdekaan Republik Indonesia. Sejarah mencatat bahwa satu-satunya provinsi yang paling otonom sebelum kemerdekaan ialah Bali. Dalam kehidupan kesehariannya, perilaku masyarakat Bali juga mendasarkan pada nilai-nilai Agama Hindu dan falsafah Tri Hita Karana. Falsafah hidup Tri Hita Karana sangat menekankan adanya keharmonisan dan keseimbangan hidup antara manusia dengan manusia, manusia dengan Sang Pencipta, dan manusia dengan lingkungannya. Prinsip-prinsip ini terinternalisasi dan terinstitusionalisasi dalam struktur sosial masyarakat Bali dan menjadi pandangan hidup masyarakat Bali, baik dalam mengembangkan sistem pengetahuan, pola-pola perilaku, sikap, nilai-nilai, tradisi, seni, dan sebagainya (Sumada, 2017)

Taru Menyan adalah nama sebuah pohon besar yang menjadi asal nama sebuah desa di Bali yaitu Desa Trunyan. Desa Trunyan adalah sebuah desa yang berada di sisi timur Danau Batur, Kabupaten Bangli, Bali. Masyarakat Desa Truyan memiliki tradisi tersendiri dalam memperlakukan keluarganya yang telah meninggal. Upacara kematian yang amat unik ini disebut dengan mepasah (Mahardika dan Darmawan, 2016). Upacara mepasah ini dipercayai memiliki makna yang sama dengan upacara ngaben pada umumnya di Bali. Tradisi ini menjadi sebuah kisah misteri penuh mitos dibalik kuburan Trunyan. Orang yang meninggal di Trunyan akan diletakkan begitu saja di kuburan Trunyan tanpa melalui proses kremasi atau penguburan. Di kuburan Trunyan mayatmayat dibiarkan begitu saja tergeletak di atas tanah dan hanya diberi penutup berupa anyaman kayu atau anyaman bambu berbentuk segitiga sama kaki (Nanda, 2016).

Secara logika jika jenazah hanya diletakkan di atas tanah, maka jenazah-jenazah tersebut tentu akan mengeluarkan bau busuk yang menyengat. Anehnya, tidak ada bau busuk yang keluar dari jenazah-jenazah yang diletakkan di area kuburan Trunyan. Lalat dan hewan lain yang biasanya menggerogoti tubuh jenazah juga tidak ada. Masyarakat setempat mempercayai keanehan ini disebabkan oleh keberadaan sebuah pohon besar terletak di tengah-tengah area kuburan (Wisangeni, 2018). Pohon besar ini bernama pohon Taru Menyan. Nama Taru Menyan didapat karena dahulu masyarakat percaya dahulu kala pohon tersebut mengeluarkan bau teramat wangi bahkan dapat tercium dari tanah Jawa. Keharuman tersebut menarik raja-raja dari Jawa untuk datang ketempat tersebut (pohon Taru Menyan) dan salah satunya menikah dengan dewi penunggu pohon tersebut. Karena raja itu tidak mau adalagi yang terhipnotis dan mencium bau wangi Pohon Taru Menyan maka raja itu memerintahkan untuk meletakkan jenazah di sekitar pohon tersebut agar wanginya tidak lagi menguarhebat (Nanda, 2016). Cerita itulah yang dipercayai oleh penduduk Desa Trunyan danterus mewariskan tradisi tersebut sehingga menjadi salah satu budaya yang khas di Bali.

Masyarakat Desa Trunyan juga memiliki beberapa aturan adat dalam menjalankan upacara mepasah. Upacaramepasah adalah untuk masyarakat Desa Trunyan Bali yang meninggal dengan cara yang wajar baik itu karena sakit atau karena usia. Mayat yang meninggal karena kecelakaan, anak kecil yang giginya belum tanggal, meninggal secara tidak wajar, dibunuh ataupun merupakan mayat orang bunuh diri dimakamkan secara dikubur.

. Kejadian di Desa Trunyan ini tentunya masih kontroversial. Mitos Taru Menyan ini perlu dikaji lebih lanjut untuk memberikan pandangan yang lebih logis terkait bau mayat yang hilang jika diletakkan di bawah pohon taru menyan tersebut. Kasus ini akan dijelaskan melalui proses inferensi ilmiah dan eksplanasi. Mengutip dari teori proses inferensi yang disampaikan Firman (2019), maka fenomena ini perlu dijelaskan melalui deduksi sehingga menemukan teori yang ilmiah untuk menjelaskan mayat yang tidak berbau busuk di bawah pohon Taru Menyan di Desa Trunyan.

\section{Metode}

Metode yang digunakan adalah metode studi kepustakaan (library research). Library research dilakukan dengan menelaah buku-buku, laporan riset, dan arti ilmiah huntuk memperkaya kajian tentang decomposition (pembusukan). Data sekunder dari berbagai hasil penelitian atau percobaan merupakan jenis data yang kemudian disintesis hingga menjadi kesatuan dalam memberikan informasi. 


\section{Hasil dan Pembahasan}

\section{Eksplansi IImiah Mayat yang Tidak Berbau}

Menurut Firman (2019) dan Ladyman (2002) dalam melakuan eksplanasi melibatkan eksplanans dan eksplanandum, namun yang membedakan adalah pola hubungan antara keduanya. Dalam mengeksplanasikan penyebab mayat yang tidak berbau di Desa Trunyan dilakukan dengan menyajikan eksplanans dari berbagai sumber terkait proses pembusukan (dekomposisi) yang terjadi pada mayat. Pembusukan merupakan sumber keluarnya gas yang menyebarkan aroma busuk pada mayat.

Menurut Dahlan (2010) dan Knight ( 1996) proses pembusukan bergantung pada variasi waktu kematiannya, tetapi pada wilayah beriklim sedang akan tampak setelah 3 hari kematian pada mayat tanpa pembekuan. Pada proses pembusukan, mayat mengamalami perusakan struktur tubuh (dekomposisi) karena enzim dan bakteri dalam tubuhnya, serta organisme dari luar tubuh. Enzim-enzim intraseluler yang dilepaskan oleh sel-sel yang sudah mati menyebabkan pencairan sel dan organ tubuh. Proses dekomposisi yang disebabkan oleh enzim ini terjadi lebih cepat saat suhu tinggi dan akan lebih lambat jika terjadi pada suhu yang rendah. Kerja enzim-enzim ini bisa diperlambat oleh pendinginan dan aktifitas enzim dapat hilang karena suhu yang sangat tinggi. Jumlah enzim yang banyak juga mempengaruhi kecepatan proses pencairan sel dan organ (Dahlan, 2000; Idries, 1997; Di Maio dan Di Maio, 1993).

Proses dekomposisi oleh bakteri terjadi dalam waktu kurang lebih 48 jam setelah waktu kematian. Bakteri dari sistem pencernaan menyebar keseluruh tubuh menyebabkan terjadinya keadaan busuk (Di Maio dan Di Maio, 1993). Pada pembusukan terjadi proses penghancuran jaringan tubuh yang terutama disebabkan oleh bakteri yang bernama Clostridium Welchii. Bakteri dan kuman-kuman pembusuk dapat masuk ke pembuluh dara dan menggunakan darah sebagai media untuk berkembang biak karena sistem pertahanan tubuh akan hilang saat sudah meninggal. Semakin banyak kuman dan bakteri berkembangbiak maka pembusukan akan terjadi semakin cepat. Kuman juga merusak jaringan-jaringan dan membentuk gas-gas pembusukan. Gas-gas pembusukan mengisi pembuluh darah menyebabkan pelebaran pada pembuluh vena sehingga pembuluh darah dan cabang-cabangnya nampak lebih jelas (Dahlan, 2000).

Setelah 336 jam dari kematian, kulit ari menjadi mulah terlepas bila tergeser atau tertekan karena terbentuk gelembung pembusukan. Gelembung pembusukan berisi cairan merah kehitaman yang disertai bau busuk. Setelah tiga atau empat minggu, rambut dan kuku akan mudah terlepas, wajah menjadi kembung dan pucat berwarna hijau kehitaman, bola mata menjadi lunak, dan cairan dekomposisi keluar dari hidung. Organ-organ dalam akan membusuk dan hancur. Organ dalam yang paling cepat busuk adalah otak, hati, lambung, usus halus, dan limpa. Otak akan lunak seperti bubur, paru-paru, hati, jantung, dan limpa akan menjadi lembek(Dahlan, 2000; Knight, 1996).

Menurut Dahlan (2000) dan Nandy (2010) terdapat dua faktor yang mempengaruhi terjadinya proses pembusukan yaitu: faktor internal dan faktor eksternal.

A. Faktor internal, yaitu:

1) Umur

Pembusukan terjadi lebih lambat pada mayat orang yang lebih tua karena lemak tubuh yang lebih sedikit. Mayat bayi yang belum pernah diberi makan juga mengalami pembusukan yang lebih lama karena kuman pembusuk belum masuk ke dalam tubuh.

2) Jenis Kelamin

Pada wanita, komposisi dengan lemak subkutan lebih banyak sehingga dapat sedikit mempercepat terjadinya pembusukan.

3) Kondisi Tubuh

Pada tubuh yang berlemak, proses pembusukan terjadi lebih cepat karena jumlah air pada tubuh yang berlemak lebih banyak sehingga memberikan tempat untuk mikroorganisme dapat berkembang.

4) Penyebab Kematian

Mayat pada penderita penyakit kronis akan lebih cepat membusuk dibandingkan dengan mayat yang mati secara mendadak. Pada mayat yang mati karena infeksi akan lebih cepat membusuk juga karena adanya bakteri.

5) Perlukaan luar pada tubuh 
Perlukaan apda tubuh dapat mempercepat proses pembusukan karena adanya mikroorganisme tembahan yang masuk kedalam tubuh melalui luka luar tubuh.

B. Faktor eksternal, yaitu:

1) Temperatur lingkungan dan tekanan atmosfer

Tekanan atmosfer dan temperatur yang tinggi dapat mempercepat proses pembusukan. Proses pembusukan paling optimal terjadi pada suhu $21^{\circ} \mathrm{C}-38^{\circ} \mathrm{C}$. Pada suhu dibawah $0^{\circ} \mathrm{C}$ atau diatas $45^{\circ} \mathrm{C}$, proses pembusukan menjadi lebih lambat karena terhambatnya pertumbuhan organisme.

2) Kelembaban

Proses pembusukan memerlukan kelembaban udara, pada kondisi dimana kelembaban udara yang tinggi dapat mempercepat proses pembusukan.

3) Udara

Pada kondisi angin yang tetap tidak akan membantu proses penguapan cairan tubuh serta laju pembusukan. Kandungan oksigen yang berkurang akan memperlambat terjadinya proses pembusukan. Oksigen diperlukan oleh bakteri aerob yang mempunyai peran dalam proses pembusukan

4) Pakaian

Pada tubuh yang tertutup pakaian dapat mencegah mikroorganisme masuk kedalam tubuh melalui udara. Saat udara dingin pakaian juga dapat mempertahankan temperatur tubuh sehingga tubuh dapat ditinggali oleh beberapa jenis mikroorganisme.

5) Medium dimana mayat berada

Pada medium udara proses pembusukan lebih cepat dibandingkan pada medium air. Pada tanah permukaan, proses pembusukan terjadi lebih cepat dibandingkan dengan tanah dalam karena jumlah bakteri lebih banyak dan tanah lebih lembab pada tanah permukaan.

6) Invasi dari hewan dan serangga

Hewan dan serangga dapat merusak tubuh mayat dan mempercepat pembusukan, dan membantu masuknya bakteri yang dapat mempengaruhi pembusukan mayat.

Miller (2002) juga mempertegas pengaruh suhu terhadap proses pembusukan. Miller menyatakan pada suhu dibawah ${ }^{\circ} \mathrm{C}$ tidak terjadi proses pembusukan. Pada suhu dibawah $4^{\circ} \mathrm{C}-12^{0} \mathrm{C}$ perkembangan bakteri menjadi lebih lambat. Suhu $15^{\circ} \mathrm{C}$ sampai $37^{\circ} \mathrm{C}$ merupakan saat yang sangat baik untuk bakteri berkembang biak. Tubuh yang hangat serta kelembaban yang cukup menjadikan proses pembusukan menjadi lebih cepat.

Melihat kondisi yang terjadi di Desa Trunyan terdapat 3 faktor eksternal yang mampu menjelaskan kenapa tidak terdapat bau busuk yang keluar dari mayat yang ditaruh di bawah pohon Taru Menyan. Faktor eksternal tersebut adalah temperatur atau suhu, udara, dan invasi dari hewan atau serangga. Dilansir dari Dony (2010), suhu udara di Desa Trunyan ada pada rentang $12^{\circ} \mathrm{C}$ sampai $17^{\circ} \mathrm{C}$. Pada suhu udara yang dingin menyebabkan laju pembusukan menjadi lebih lambat sesuai dengan temuan Miller (2002). Menurut Dahlan (2000) dan Nandy (2010) udara yang tetap tidak dapat membantu proses penguapan cairan tubuh dan laju pembusukan. Kondisi pohon Taru Menyan yang rindang membuat daun dan rantingnya menutupi seluruh area makan, ditambah pohon lebat lain disekelilingnya membuat aliran udara tidak terlalu bagus. Ridangnya pohon ini juga menjaga suhu udara di bawah pohon tetap dingin meskipun pada siang hari. Keadaan lingkungan inilah yang menyebabkan laju pembusukan menjadi lambat dan penguapan gas dari cairan tubuh menjadi lambat sehingga bau busuk seperti mayat pada umumnya tidak tercium disana. Serangga seperti lalat juga tidak ditemukan diarea makam seperti yang dapat dilansir dari Wisangeni (2018). Menurut Dahlan (2000) faktor serangga dapat membantu proses pembusukan karena merusak kulit luar mayat dan menyebabkan bakteri masuk dengan cepat. Dengan tidak adanya serangga seperti lalat, maka otomatis laju pembusukan menjadi melambat. 


\section{Kesimpulan}

Bau busuk pada mayat disebabkan oleh gas yang menguap dari proses pembusukan pada mayat tersebut. Proses pembusukan dipengaruhi oleh faktor eksternal dan faktor internal. Faktor eksternal yang mempengaruhi laju pembusukan pada mayat adalah (1) temperatur/suhu, (2) kelembaban, (3) udara, (4) pakaian, (5) medium tempat mayat, dan (6) invasi hewan lain. Faktor internal yang mempengaruhi proses pembusukan diantaranya (1) umur, (2) jenis kelamin, (3) kondisi tubuh, (4) penyebab kematian, dan (5) perlukaan luar tubuh. Dari kondisi mayat yang diletakan di bawah pohon Taru Menyan, terdapat 3 faktor eksternal yang menyebabkan laju pembusukan melambat, yaitu: (1) temperatur/suhu, (2) udara, dan (3) invasi hewan lain. Faktor inilah yang membedakan lingkungan makan di desa trunyan dengan desa lain di Bali sehingga mayat yang diletakkan disana tidak berbau.

\section{Daftar Pustaka}

Dahlan, S. 2000. Ilmu Kedokteran Frensik Pedoman Bagi Dokter dan Penegak Hukum. Semarang: Badan Penerbit Universitas Diponegoro.

Di Maio, D. J., \& Di Maio, V. J. 1993. Time of Death; Forensic Pathology. CRC Press, Inc.

Dony. 2010. Kintamani. Diakses di https://dony.blog.uns.ac.id/2010/06/02/kintamani/ pada tanggal 25 Maret 2019

Firman, H. 2019. Pengantar Filsafat Ilmu Pengetahuan Alam. Bandung: SPS UPI

Idries, A. 1997. Pedoman Ilmu Kedokteran Forensik. Jakarta: Binarupa Aksara.

Knight, B. 1996. Forensic Pathology. New York: Oxford University Press Inc.

Nanda, I. B. U. J. 2016. Semawayahsebagaisumberinspirasidalamberkaryasenilukis di DesaTrunyan - Bali. Dokumentasi. ISI Denpasar.Diakses di http://repo.isi-dps.ac.id/2265/ pada 25 Maret 2019

Ladyman, J. 2002. Understanding Philosophy of Science. London: Routledge

Mahardika, I W. T., \& Darmawan, C. 2016. Civic culture dalam nilai-nilai budaya dan kearifan lokal masyarakat Bali Aga Desa Trunyan. Humanika. Vol 23 (1): hal 20-31

Miller, R. A. 2002. The Affects of Clothing on Human Decomposition:Implications for Estimating Time Since Death.Thesis. University ofTenessee.

Nandy, A. Purba. 2010. Principles of Forensic Medicine. English: New Centra Book Agency.

Sastrapratedja, M. 1982. Manusia Multi Dimensional: Sebuah Renungan Filsafat. Jakarta: Gramedia.

Sukarma, I Wayan. 2017. Pengembangan Kearifan Lokal Seni Budaya Melalui Pendidikan Berbasis Banjar Di Bali. https://jurnal.uns.ac.id/icalc/article/view/16046/13134. Diakses 9 Mei 2019

Sumada, I Made. 2017. Peranan Kearifan Lokal Bali Dalam Perspektif Kebijakan Publik. https://jipsi.fisip.unikom.ac.id/_s/data/jurnal/volume7no1/11-i-made-sumada.pdf/pdf/11-imade-sumada.pdf. Diakses 9 Mei 2019.

Tirtarahardja, Umar dan La Sulo. S.L. 1985. Pengantar Pendidikan. Jakarta: Rineka Cipta.

Wisangeni, K. 2018. Cerita misteri kuburan Trunyan di Bali by Kensae. Tanah Nusantara. Diakses di https://www.tanahnusantara.com/cerita-misteri-kuburan-trunyan-di-bali/ pada 25 Maret. 